\title{
Tissue acquisition for diagnosis of proximal biliary lesions using endoscopic ultrasound-guided fine-needle aspiration
}

\author{
Vikas Singla', RaviDaswani', Anil Arora', Kusum Verma', Mandhir Kumar', Piyush Ranjan', \\ Pankaj Puri', Ashish Kumar', Pooja Bakshi', Naresh Bansal', Munish Kumar Sachdeva', \\ Praveen Sharma', Shrihari Anil Anikhindi', Rachit Agarwal ${ }^{4}$, Shivam Khare'
}

'Institute of Liver, Gastroenterology and Pancreaticobiliary Sciences, Sir Ganga Ram Hospital, New Delhi, ${ }^{2}$ Department of Cytopathology. Sir Ganga Ram Hospital, New Delhi, India

${ }^{3}$ Liver and Digestive Disease Institute. Fortis Escorts New Delhi, India.

${ }^{4}$ Institute of Gastro Sciences, Apollo Gleneagles Hospital, Kolkata, India

\section{A B S T R A C T}

\begin{abstract}
Objectives: To report the diagnostic yield and safety of endoscopic ultrasound-guided fine-needle aspiration (EUS FNA) for the evaluation of proximal bile duct lesions.

Materials and methods: A retrospective analysis of data of the patients, who had undergone EUS for proximal bile duct lesions was done. FNA was performed from either the bile duct mass, enlarged node, or liver lesions. Outcome measures were the diagnostic yield of EUS FNA and adverse events.

Results: From April 2011 to August 2018, 147 patients with suspected proximal bile duct malignancy underwent EUS. Mass lesion was seen in $133(90.47 \%)$ patients. FNA was performed in $125(85.03 \%)$ patients. The final diagnosis in patients undergoing EUS FNA was malignancy in 118 , benign disease in six, and one patient was lost to follow up. EUS FNA confirmed the diagnosis in 103/118 patients with malignancy (sensitivity $87.28 \%$ ); was false negative in $15 / 118$ cases with malignancy, and was truly negative in all the six patients with benign disease (specificity $100 \%$ ). Positive predictive value, negative predictive value, and the accuracy of EUS FNA were $100 \%, 28.57 \%, 87.90 \%$ respectively. No serious adverse event was reported, five patients had self-limiting pain.

Conclusion: EUS FNA is a sensitive tool for the evaluation of proximal bile duct lesions. Low negative predictive value warrants further evaluation in patients with non-malignant findings on cytology.

Keywords: Endoscopic ultrasonography, fine needle aspiration, proximal biliary obstruction

JMS: 2020; 23(2):9-19 DOI: https://doi.org/10.33883/jms.v23i2.765
\end{abstract}

\section{INTRODUCTION}

Proximal bile duct lesionsremain challenging to diagnose and treat, available diagnostic modalities have limited accuracy. Though the malignancies such as cholangio carcinoma and carcinoma gallbladder are the most common cause, ${ }^{1,2}$ benign diseases such as Mirrizzi syndrome, postcholecystectomy injury, xanthogranulomatous cholecystitis, and primary sclerosing cholangitis can also cause proximal biliary obstruction. ${ }^{1,3,4}$ Available diagnostic imaging cannot differentiate malignant and benign lesions accurately, hence pathological studies are necessary. Establishing pathological diagnosis for resectable lesions

\begin{tabular}{|l|l|}
\hline \multicolumn{2}{|c|}{ Access this article online } \\
\hline
\end{tabular}

undergoing surgery remains a debatable issue. Because of limited sensitivity and fear of needle tract seedling, surgery is often performed without tissue diagnosis if the probability of malignancy is high. It is mandatory to have tissue diagnosis for unresectable lesions, as most of these patients have advanced disease and the treatment option is

Correspondence:

Dr. Vikas Singla, DM

Institute of Liver, Gastroenterology \& Pancreaticobiliary Sciences, Sir Ganga Ram Hospital, Rajinder Nagar, New Delhi, India, 110060

Email: singlavikas1979@gmail.com

How to cite this article: Singla V, Daswani R, Arora A, Verma K, Kumar M, Ranjan P, Puri P, Kumar A, Bakshi P, Bansal N, Sachdeva MK, Sharma P, Anikhindi SA, Agarwal R, Khare S. Tissue acquisition for diagnosis of proximal biliary lesions using endoscopic ultrasound-guided fine-needle aspiration. JMS 2020; 23(2): 9-19

Received: 2020-05-25 Accepted: 2020-06-12

(ㅇ) (1) This is an open-access article distributed under the terms of the Creative Commons Attribution License (CC BY 4.0), which permits unrestricted use, distribution, and reproduction in any medium, provided the original author and source are credited. 
Singla V, et al, Tissue acquisition for diagnosis of proximal biliary lesions using endoscopic ultrasound-guided

limited to palliative biliary drainage and chemotherapy. Endoscopic retrograde cholangio pancreatography (ERCP) guided brushings and biopsy have been the most common modality used for the proximal cholangiocarcinoma, but the yield remains low. ${ }^{5,67}$ Endoscopic Ultrasound (EUS)though initially established for pancreatic and distal bile duct lesions, has been increasingly used for proximal biliary tract lesions also. In most of the published studies, the number of patients with proximal biliary obstruction was low, and EUSFNA was performed after the failure of ERCP to establish the diagnosis. ${ }^{8,9,10,11}$ We are using EUS as the first modality for the pathological diagnosis of proximal bile duct lesions, and ERCP is reserved for therapeutic purposes. The aim of the present study is to report the efficacy of the safety of EUS FNA in patients with proximal bile duct lesions.

\section{PATIENTS AND METHODS}

The present study is the retrospective analysis of the prospectively collected database. At our center, a tertiary care referral center for endoscopic procedures, EUS is routinely performed for proximal biliary obstruction. From April 2011 to August 2018, data of all the patients who underwent EUS for proximal biliary obstruction were prospectively entered in a database. The proximal biliary obstruction was defined as blockage or compression above the level of insertion of the cystic duct. We reviewed the database for collecting the following data: patient demographics, EUS findings, adverse events related to the procedure, pathological results of EUS FNA, results of other modalities for tissue diagnosis (ERCP brushings, percutaneous FNA, and surgical specimen), results of follow up. Institutional Review Board at our center approved the study. (EC/04/19/1516)

All adult patients with proximal biliary obstruction due to primary biliary lesions and suspicion of malignancy were included in the study. Gallbladder cancer is a common differential diagnosis for lesion causing proximal biliary obstruction. The mass lesions with predominant involvement of gallbladder were considered as arising from the gallbladder and were excluded (gallbladder lesions were analyzed separately and has been published previously ${ }^{13}$ ). Other exclusion criteria included pregnancy, previous diagnosis of biliary malignancy, thrombocytopenia $(<50,000 / \mathrm{L})$, prolongation of prothrombin time by more than 4 seconds, international normalized ratio $>1$.5. Patients with a benign disease such as bile duct stone, mirizzi syndrome, and portal biliopathy were also excluded.

During the EUS examination, the lesion was defined as resectable if there was an absence of ascites, absence of involvement of hepatic artery/portal vein, absence of liver metastasis, and no enlargement of non-regional nodes. Lesions that would confer a higher stage were targeted before the primary mass. In unresectable lesions, FNA was taken either from the tumor, lymph node, or liver lesion. If the patient was considered for a liver transplant, FNA from the primary tumor was avoided. In the case of resectable lesions, FNA was obtained from regional lymph node; and in the absence of enlarged lymph nodes, FNA from primary lesions was carried out only if specifically requested for by the patient and/or the treating surgeon.

\section{EUS Technique}

Written informed consent was obtained from the patient before the procedure. Moderate sedation was given with the combination of midazolam and pentazocine.

EUS examinations were performed by experienced endoscopists (VS/MK/AA), who had performed more than 2000 EUS examinations each. All the cases were performed with the linear array echoendoscope (GF UCT 180, Olympus Medical Systems Corp, Tokyo, Japan) in the left lateral position. After evaluation from the esophagus and stomach, an echoendoscope was introduced in the first part of the duodenum and stabilized at the junction of the first and second parts of the duodenum. Portal vein and lower common bile were focused from the first part of the duodenum, after localization, common bile duct (CBD) was traced towards liver hilum by anticlockwise rotation and pull back maneuver. Either the bile duct or intrahepatic radical were traced towards the lesion, which usually have echo texture different from the surrounding tissue (Figure 1\&2). The tumor was evaluated for the involvement of a common hepatic artery or main portal vein, liver metastasis, or lymph node enlargement. Vascular involvement by tumor was considered to be present if any of the following were noted: loss of the hyperechoic interface between tumor and vessel, tumor thrombus within the vessel lumen, vessel encasement. Doppler examination was performed prior to FNA to rule out any intervening vessel. FNA was obtained either from primary mass, liver lesions or from the 
Singla V, et al, Tissue acquisition for diagnosis of proximal biliary lesions using endoscopic ultrasound-guided

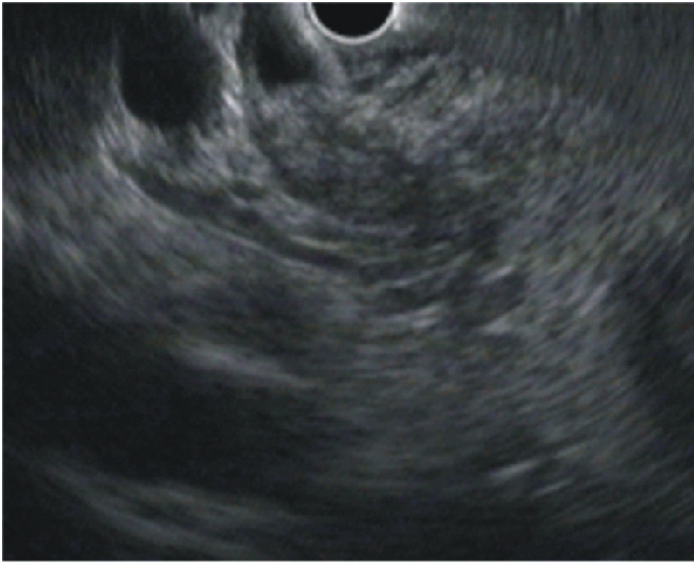

Fig. 1: Mass with well-defined margins blocking the proximal bile duct

metastatic appearing node (Figure 3). A 22 G Needle was used for the sampling (Echotip Ultra, Cook Ireland Ltd, Limerick, Ireland, or Expect Slim line, Boston Scientific Corp, MA USA), the stylet was not used. The lesion that would confer the highest stage was preferentially targeted. At least four passes were made during each procedure, the needle was moved for 8-10 times during each pass. Suction was not used routinely unless the first pass had insufficient material. After aspiration, the material was expressed on slides and both alcohol's fixed and air-dried slides were prepared. Rapid onsite cytology examination (ROSE) was not performed routinely. A final cytological diagnosis was made by an experienced team of cytopathologists (KV/PB). Confirmation of metastasis to the lymph node or liver was considered sufficient for the diagnosis of malignancy, irrespective of whether the primary tumor was targeted or FNA was negative from the primary tumor site.

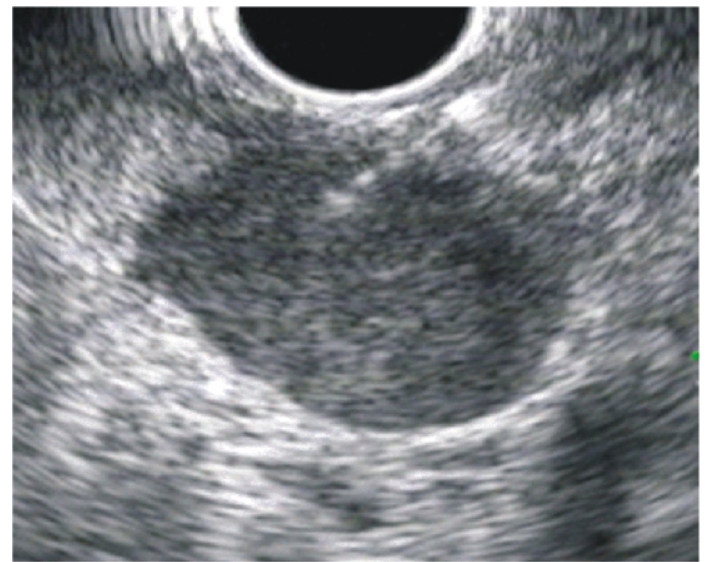

Fig. 3: Enlarged round node in pericholedochal region

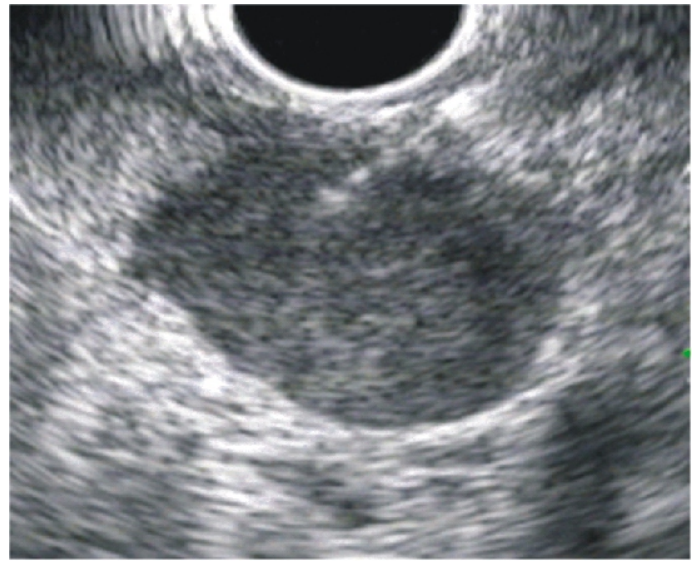

Fig. 2: Mass with ill-defined margins blocking the proximal bile duct

Patients were discharged on the same day after the procedure and were advised to visit the emergency room or contact primary physicians in case of development of newonset or worsening of pain, fever, or GI bleed. In the case of new-onset pain, imaging was performed to rule out bile leak. New-onset fever in the absence of other possible etiology was attributed to cholangitis. Cholangitis occurring within 7 days of EUS FNA was considered to be procedure-related.

\section{Final Diagnostic Criteria and outcome parameters}

For the evaluation of EUS findings, the presence of mass lesion was considered as an indicator of malignancy, which was tested against the final diagnosis.

EUS FNA diagnosis was categorized as malignant or nonmalignant which was tested against the final diagnosis.

FNA reports were categorized as diagnostic of malignancy (Figure 4), suspicious of malignancy, atypical cytology,

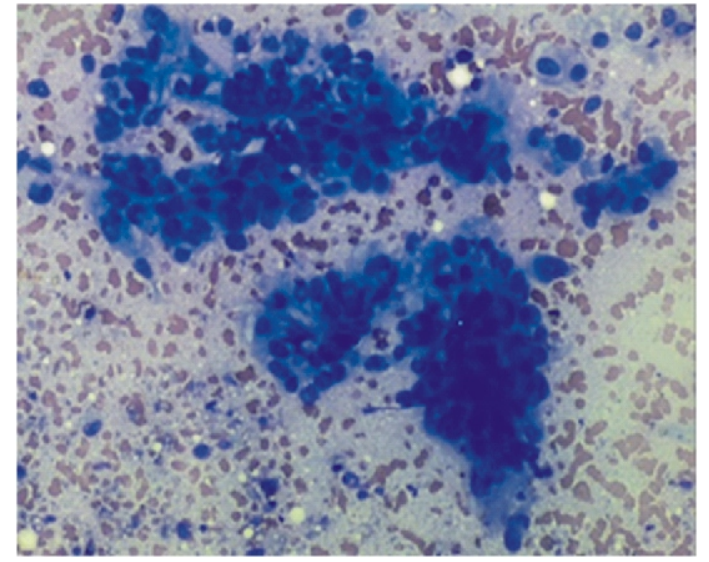

Fig. 4: Cytology smear of proximal CBD mass showing fragments of tumor cells with the focal glandular arrangement (Giemsa stain, magnification 200x) 
Singla V, et al, Tissue acquisition for diagnosis of proximal biliary lesions using endoscopic ultrasound-guided

inconclusive or benign disease. For the evaluation of EUS performance, specimens reported as diagnostic of malignancy were categorized as malignant, all other reports (suspicious/inconclusive/atypical or benign) were considered as nonmalignant. Lymph node FNA reports were categorized as malignant and reactive (nonmalignant).

A final diagnosis of malignancy was made if there was definite evidence of malignancy on the EUS FNA sample, ERCP brushings, percutaneous sampling of the lesion, or surgical specimen. In the absence of the pathological diagnosis, a compatible clinical course was taken as evidence of malignancy. Significant clinical worsening during one year follow up was considered as diagnostic of malignant disease. Patients who were lost to follow up were not considered for final analysis. In the patients undergoing FNA more than once, the diagnosis of final FNA was considered for the analysis.

\section{Statistical analyses}

Categorical variables were expressed as frequencies and percentages and continuous variables as mean and standard deviation. Sensitivity, specificity, diagnostic accuracy, positive and negative predictive values of EUS findings, and EUS FNA were calculated. The sensitivity and specificity of EUS FNA were calculated as the proportion of malignant and non-malignant FNA amongst all malignant and benign cases respectively. Positive predictive and negative predictive values were calculated as the proportion of true positive amongst all positive cases and the proportion of true negative amongst all negative cases. Accuracy was defined as the percentage of patients correctly classified by FNA against the final diagnosis. Similarly, the presence or absence of mass lesion was tested against the final diagnosis.

SPSS 17.0 software was used for analysis.

\section{RESULTS}

\section{Baseline parameters and final diagnosis}

306 patients, underwent EU Sevaluation for proximal biliary obstruction (Figure 5, Flow chart). Out of these, 159 were excluded, and 147 patients were suspected to have proximal biliary obstruction due to primary biliary lesions. Demographic details and EUS findings of all the patients are mentioned in table 1. The final diagnosis was malignancy in 132 patients; cholangiocarcinoma was the most common diagnosis (125), followed by hepatocellular carcinoma (HCC) (2), lymphoma (2), neuroendocrine tumor (3). 4 patients had tuberculosis, and 4 patients had benign stricture, all these 8 patients were considered to have the benign disease for final analysis, 7 patients were lost to follow up.

\section{EUS findings}

133 patients had mass lesions on EUS, and the final diagnosis was available in 128 patients (123 malignant, 5

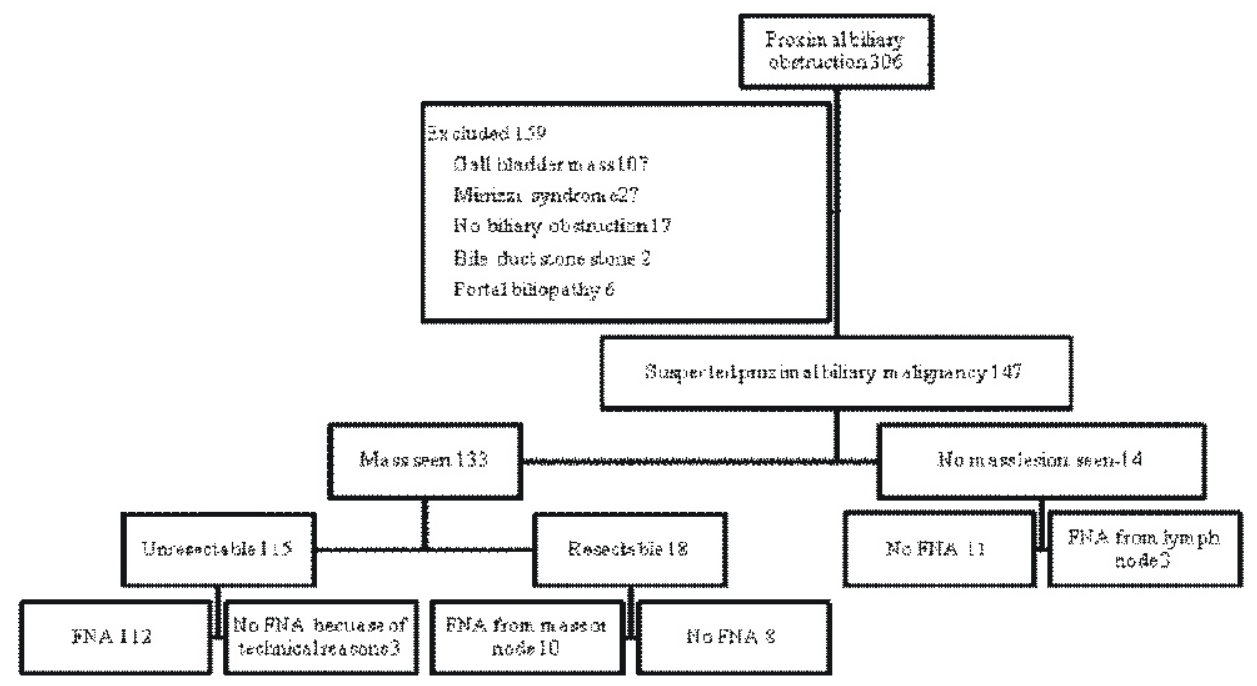

Fig. 5: Patient disposition, patients with gall bladder lesions and benign diseases were excluded FNA: Fine-needle aspiration 
Singla V, et al, Tissue acquisition for diagnosis of proximal biliary lesions using endoscopic ultrasound-guided

Table 1: Demography and baseline characteristics of the patients, $n-147$

\begin{tabular}{|l|l|}
\hline Age(years) mean \pm sd & $59.34 \pm 13.18$ \\
\hline Sex M:F & $94: 53$ \\
\hline Bilirubin (mg/dL)mean \pm sd & $9.41 \pm 5.86$ \\
\hline $\begin{array}{l}\text { Serum Alkaline Phosphatase } \\
(\mathrm{IU} / \mathrm{L}), \text { mean } \pm \text { sd }\end{array}$ & $538.67 \pm 376.87$ \\
\hline Resectable lesions, $\mathrm{n}(\%)$ & $32 / 147(21.76 \%)$ \\
\hline Primary confluence blocked, $\mathrm{n}(\%)$ & $93 / 54$ \\
\hline $\begin{array}{l}\text { Number of patients requiring more } \\
\text { than one FNA, } \mathrm{n}(\%)\end{array}$ & $2(1.66 \%)$ \\
\hline Size of the mass (mm)mean \pm sd & $28.20 \pm 13.17$ \\
\hline $\begin{array}{l}\text { Mass with well-defined margins, } \mathrm{n} \\
(\%)\end{array}$ & $31(21.08 \%)$ \\
\hline Mass with irregular margins, $\mathrm{n}(\%)$ & $105(71.42 \%)$ \\
\hline No mass lesion seen, $\mathrm{n}(\%)$ & $11(7.48 \%)$ \\
\hline $\begin{array}{l}\mathrm{n}-\text { number, sd- standard deviation, dL- deci-litre, IU- International } \\
\text { Units, L- Litre, mm- millimeter }\end{array}$
\end{tabular}

benign). 14 patients had no mass, and a final diagnosis could be reached in 12 patients ( 9 malignant, 3 benign). Out of the 132 patients with a final diagnosis of malignancy, the mass lesion was seen in 123 patients. So the sensitivity of EUS alone without FNA for detection of malignancy is $93.18 \%$. In 8 patients with benign disease, 3 patients had no mass lesion at the site of narrowing. The specificity of the absence of mass lesion as an indicator of benign disease was low(37.5\%\%). Amongst 128 patients with the mass lesion, 123 had a final diagnosis of malignancy, the positive predictive value of mass lesion for diagnosis of malignancy was $96.09 \%$. Negative predictive value and accuracy were $25 \%$, and $90 \%$ respectively.

\section{Performance of EUS FNA}

Out of 125 patients undergoing FNA, 108 patients had FNA from one site; FNA was taken only from the biliary lesion in 80 patients, and only from the node in 28 patients. Seventeen patients had FNA from 2 sites; 16 patients had FNA from the mass along with the nodes, and one patient had FNA from both liver and lymph node. FNA outcome and final diagnosis of these patients are mentioned in table 2. In patients undergoing FNA, the final diagnosis was malignancy in 118 patients, 6 patients had benign disease, and one patient was lost to follow up. EUS FNA was positive for malignancy in 103 patients and was negative in all cases with benign disease. The sensitivity and specificity of EUS FNA for diagnosis of malignancy were $87.28 \%$
(103/118) and 100\% (6/6) respectively. Amongst 21 patients with negative cytology, the final diagnosis was a benign disease in only 6 patients, negative predictive value was $28.57 \%$. Positive predictive value and accuracy were $100 \%$ and $87.90 \%$ respectively. The final diagnosis of patients not undergoing FNA is mentioned in table 3. Amongst 132 patients with malignancy, FNA could establish a diagnosis in 103 patients (78.03\%).

\section{Adverse Events}

No procedure-related serious adverse events such as perforation, bleed, or cholangitis occurred. Self-limiting mild pain occurred in five patients. No significant collection was seen on imaging in these patients.

\section{DISCUSSION}

Endoscopic retrograde cholangiography guided sampling techniques are the most common modalities for tissue diagnosis of proximal biliary strictures. EUS has emerged as auseful tool for the evaluation of proximal biliary lesions, especially after failing to make a diagnosis with ERCP. Irrespective of whether ERCP or EUS is performed for tissue diagnosis, the need for pathological diagnosis depends upon the resectability status of lesions also. Upfront surgery fora biliary lesion with high suspicion of malignancy can be performed without the pathological diagnosis, reasons are limited accuracy of ERCP based diagnostic modalities, and risk of needle track seedling with the EUS FNA. This approach is associated with the more 
Singla V, et al, Tissue acquisition for diagnosis of proximal biliary lesions using endoscopic ultrasound-guided

Table 2: Outcome of FNA and final diagnosis lesions undergoing FNA, n 125

\begin{tabular}{|c|c|c|}
\hline & FNA diagnosis & Final Diagnosis \\
\hline \multirow[t]{4}{*}{$\begin{array}{l}80 \text { FNA from biliary } \\
\text { mass only }\end{array}$} & $\begin{array}{l}70 \text { adenocarcinoma } \\
2 \text { neuroendocrine tumor } \\
1 \text { hepatocellular } \\
\text { Carcinoma }\end{array}$ & 73 malignant \\
\hline & 3 suspicious & 3 malignant: compatible clinical course \\
\hline & 2 inconclusive & $\begin{array}{l}2 \text { malignant } \\
\text { One Surgical specimen } \\
\text { One positive brush cytology }\end{array}$ \\
\hline & 2 benign & $\begin{array}{l}2 \text { malignant } \\
1 \text { compatible clinical course } \\
1 \text { surgical specimen }\end{array}$ \\
\hline \multirow{7}{*}{$\begin{array}{l}28 \text { FNA from lymph } \\
\text { node }\end{array}$} & 14 malignant & 14 malignant \\
\hline & 3 tuberculosis & 3 tuberculosis \\
\hline & 1 neuroendocrine Tumor & 1 neuroendocrine Tumor \\
\hline & $\begin{array}{l}1 \text { hepatocellular } \\
\text { Carcinoma }\end{array}$ & 1 hepatocellular Carcinoma \\
\hline & 2 lymphoma & 2 lymphoma \\
\hline & 2 inconclusive & 2 malignant: compatible clinical course \\
\hline & 5 reactive & $\begin{array}{l}4 \text { malignant } \\
3 \text { compatible clinical course } \\
1 \text { positive brush cytology } \\
1 \text { benign-compatible clinical course }\end{array}$ \\
\hline \multirow[t]{5}{*}{$\begin{array}{l}16 \text { from biliary mass } \\
\text { and lymph node }\end{array}$} & $\begin{array}{l}10 \text { - both mass and node } \\
\text { malignant }\end{array}$ & 10 malignant \\
\hline & $\begin{array}{l}1 \text { mass malignant, node } \\
\text { reactive }\end{array}$ & 1 malignant \\
\hline & $\begin{array}{l}1 \text { both mass and node } \\
\text { Tuberculosis }\end{array}$ & 1 tuberculosis \\
\hline & $\begin{array}{l}1 \text { mass suspicious, node } \\
\text { reactive }\end{array}$ & 1 malignant - positive brush cytology \\
\hline & 3 benign from both sites & $\begin{array}{l}1 \text { malignant - compatible clinical course } \\
1 \text { benign-compatible clinical course } \\
1 \text { lost to follow up }\end{array}$ \\
\hline $\begin{array}{l}1 \text { FNA from both } \\
\text { node and liver }\end{array}$ & Both malignant & 1 malignant \\
\hline Overall & $\begin{array}{l}103 \text { malignant, } 22 \text { non } \\
\text { malignant }\end{array}$ & $\begin{array}{l}118 \text { malignant (103 FNA, } 10 \text { compatible clinical } \\
\text { course, } 3 \text { ERCP brush, } 2 \text { surgical specimen), } \\
\text { Benign } 6 \text { ( } 4 \text { Tuberculosis, } 2 \text { benign- compatible } \\
\text { clinical course), } \\
1 \text { lost to follow up, }\end{array}$ \\
\hline
\end{tabular}

n- number, FNA- fine needle aspiration 
Singla V, et al, Tissue acquisition for diagnosis of proximal biliary lesions using endoscopic ultrasound-guided

Table 3: Final diagnosis in patients not undergoing FNA, n 22

\begin{tabular}{|l|l|}
\hline No mass seen & 7 Malignant \\
n-11 & 2 positive brush cytology \\
& 2 percutaneous FNA positive \\
& 3 compatible clinical course \\
& 2 benign \\
1 benign surgical specimen \\
1 compatible clinical course \\
Mass seen but FNA not & 2 lost to follow up \\
performed, n11 & 3 positivnant \\
Resectable 8 & 2 compatible clinical course \\
Technical 3 & 1 percutaneous FNA positive \\
& 1 surgical specimen \\
& 4 lost to follow up \\
\hline Total $\mathrm{n} 22$ & 14 malignant \\
& 2 benign disease \\
& 6 lost to follow up. \\
\hline
\end{tabular}

n- number, FNA- fine needle aspiration

radical surgery in $5-25 \%$ of patients with benign disease. ${ }^{1,1,19}$ We prefer upfront surgery for resectable lesions if the clinical course is compatible with the diagnosis of malignancy. FNA is performed if the possibility of benign disease is high, which is suspected in younger patients, or if large or necrotic nodes are seen, suggesting a diagnostic possibility of lymphoma or tuberculosis, or pancreas is diffusely bulky suggesting autoimmune pancreatitis with cholangiopathy. In our study, 15 patients were diagnosed to have diseases that are either curable without surgery or have a better prognosis, such as HCC, tuberculosis, lymphoma, neuroendocrine tumor, or benign stricture. The treatment options are limited for unresectable lesions, most of these patients are treated by chemotherapy, biliary drainage, or palliative care. Hence the tissue diagnosis becomes necessary before chemotherapy or for counseling the patient and the family regarding the potentially incurable disease.

EUS has been increasingly used for the evaluation of proximal bile duct lesions. In the initial studies, EUS was performed after the failure of ERCP to establish a diagnosis. Raven et $\mathrm{al}^{8}$ first published case series of ten patients of resectable hilar cholangiocarcinoma, adequate material was obtained in 9 patients, eight patients had malignant lesions, and one was a false negative. Table 4 summarizes the yield of various EUS FNA studies for proximal biliary stricture. In most of these studies, EUS FNA was performed after the failure of ERCP based modalities to establish the tissue diagnosis. Our studies results are close to studies with higher sensitivity, this may be due to our preference for EUS FNA in unresectable lesions, which are more likely to be larger, hence can be easily seen and sampled. Tellez Avila et $\mathrm{al}^{14}$ reported the outcome of EUS FNA as the first modality in 39 patients, tissue diagnosis was obtained in 32 patients (82.1\%), The sensitivity and specificity of EUS-guided sampling was $79 \%$ and $100 \%$, the positive and negative predictive values were 100 and $41.6 \%$, respectively, and the accuracy was $82 \%$.A large meta-analysisof EUS FNA for biliary stricture has shown a sensitivity of $80 \%$ and specificity $97 \%$. Sensitivity was higher for distal than proximal stricture $(83 \text { vs } 76 \% \%)^{20}$.

ERCP has been the most common modality for the CBD lesion sampling, but the diagnostic accuracy is low. ${ }^{6,721-24}$ The large review has shown a sensitivity of $41.6 \%$ and a negative predictive value of $58 . \%{ }^{25}$ The diagnostic yield for biliary cytology can be increased to $6070 \%$ by using both brushings and biopsies. ${ }^{23,24}$ ERCP and EUS based diagnostic modalities have been compared previously. Weilert et $\mathrm{al}^{15}$ reported higher sensitivity of EUS FNA than ERCP for pathological diagnosis. On subgroup analysis, authors, found EUS FNA more sensitive than ERCP for pancreatic strictures, however for biliary strictures, both were comparable. Rosch et $\mathrm{al}^{12}$ compared ERCP and EUS guided sampling and found the higher yield of ERCP and EUS for 
Singla V, et al, Tissue acquisition for diagnosis of proximal biliary lesions using endoscopic ultrasound-guided

Table 4: Published studies on the outcome of EUS FNA for proximal bile duct lesions

\begin{tabular}{|l|l|l|l|l|}
\hline & Proximal lesion-n & Final diagnosis & Sensitivity & Specificity \\
\hline Raven et al $^{8}$ & 10 & 10 malignant & $80 \%$ & \\
\hline Raven et al & 44 & 36 malignant, benign 8 & $89 \%$ & $100 \%$ \\
\hline Dewitt & 24 & 22 malignant, 2 benign & $77 \%$ & $100 \%$ \\
\hline Eloubeidi et al $^{11}$ & 15 & Not specified & & \\
\hline Rosch et al $^{12}$ & 11 & 4 malignant, 7 benign & $25 \%$ & $100 \%$ \\
\hline Tellez Avila $^{14}$ & 39 & 34 malignant, 5 benign & $77 \%$ & $100 \%$ \\
\hline Weilert et al $^{15}$ & 7 & 7 malignant & $86 \%$ & - \\
\hline Mohmadnejad et al $^{16}$ & 30 & 30 malignant & $59 \%$ & - \\
\hline Nayar et al & 32 & 24 malignant, 8 benign & $52 \%$ & $100 \%$ \\
\hline Present Study & 124 & 118 malignant, benign 6 & $87.28 \%$ & $100 \%$ \\
\hline
\end{tabular}

EUS - endoscopic ultrasonography, FNA - fine needle aspiration

biliary and pancreatic lesions respectively. The low yield in the study for EUS for biliary lesions was due to the failure of visualization of the lesions, hence FNA could not be obtained. Hence in patients, where EUS fails to demonstrate a mass or FNA is not feasible, ERCP can be performed. Direct cholangioscopy is another important tool for the evaluation of biliary strictures. A recent study by Lee et $\mathrm{al}^{26}$ has shown high accuracy of per-oral cholangioscopy and biopsy $(93.6 \%)$, for the detection of malignancy in proximal biliary strictures after the failure of ERCP and forceps biopsy. So ERCP Biopsy, Cholangioscopy biopsy, and EUS guided FNA/FNB all are important modalities for proximal stricture, the decision to choose depends upon the availability, resectability status, and the need for biliary drainage. If biliary drainage is not required, EUS FNA can be used as the first modality, as ERCP and cholangioscopy are likely to increase the risk of complications. ${ }^{27}$

It's worth mentioning here of a special situation of unresectable hilar cholangiocarcinoma, which is being increasingly treated with neoadjuvant chemoradiotherapy followed by liver transplantation. ${ }^{28,29}$ Because of the risk of needle track seeding, transperitoneal (percutaneous or EUS guided) FNA of primary tumor should not be attempted in this subset of patients. In a series of patients undergoing liver transplant for unresectable hilar cholangiocarcinoma, 5 out of $6(83 \%)$ patients underwent transperitoneal sampling, had evidence of peritoneal metastasis during a pretransplant laparoscopic evaluation, compared to 14 out of 179 patients $(8 \%)$ who did not have pretransplant sampling, $(\mathrm{p}=0.0097) .{ }^{30}$ Hence percutaneous or EUS guided sampling should be avoided in this group of patients. Node positivity precludes liver transplantation in patients with hilar cholangiocarcinoma. Gleeson et $\mathrm{al}^{31}$ performed EUSFNA in patients with hilar cholangiocarcinoma being considered for liver transplantation and $17 \%$ of patients were spared the cost and morbidity of an unnecessary staging laparotomy.

Negative predictive value of the EUS FNA in the present study is low, which suggests that these patients should be closely followed up, tissue diagnosis may be attempted with other techniques, and surgery may be performed if the diagnostic uncertainty persists.

We found EUS FNA as a safe modality for the proximal biliary lesions, without any serious adverse event in our cohort of patients. Avoiding the FNA through vessels or patent biliary system/gall bladder seems to be the key to avoid serious complications.

The limitation of the present study is that we have not taken surgical specimens as a gold standard, as surgery is not recommended in patients with vascular or non-regional nodal involvement. Moreover, previous studies have shown that false-positive results are very uncommon with the EUS FNA, so this is unlikely to affect the final result.

Because of retrospective nature, there are inherent limitations to the present study. Some of the adverse events in our patients may have been missed, however, we had advised the patients to follow up in an emergency in case of any new onset symptom. So, it's unlikely that significant adverse events may have been missed in the present study. The involvement of vascular structures based on EUS findings in the present study could not be confirmed with either CT scan or surgical findings, as the complete data 
Singla V, et al, Tissue acquisition for diagnosis of proximal biliary lesions using endoscopic ultrasound-guided

were not available.

The strength of the present study is the large sample size, where the EUS has been performed for a uniform population of the patients with proximal bile duct mass, and preferential sampling in unresectable lesions, a condition where tissue diagnosis is mandatory. We performed EUS as an upfront modality, rather than after the failure of other modalities, which reflect the true performance of EUS in this group of patients.

To conclude, the sensitivity of EUS FNA for proximal bile duct lesions is high, but because of low negative predictive value, lesions negative for malignancy need close follow up and should be evaluated with other modalities. Hence EUS has the potential to become a primary modality for evaluation of proximal biliary lesions and needs to be compared with ERCP guided modalities and cholangioscopic biopsy.

Acknowledgment: We acknowledge the contribution of Meetu Sharma in the compilation of the data.

Conflict of Interests: All the authors declared no conflict of interest.

Financial Support : Nil

Written Informed consent : Taken

\section{What is known in the topic?}

- $\quad$ EUS is established modality for the distal end common bile duct obstruction

- $\quad$ Limited data is available for the lesions with proximal biliary obstruction

- Previous studies have used EUS FNA after failure of ERCP to establish the diagnosis

\section{What is new in the study}

- EUS is efficacious and safe modality to establish the tissue diagnosis in patients with proximal biliary obstruction

- $\quad$ EUS with FNA can be a first diagnostic modality in patients with proximal biliary obstruction

- Negative predictive value of EUS FNA for is low, suggesting further evaluation in these patients, if FNA is negative for malignancy

\section{Abbreviations}

CBD: Common bile duct
CT: Computed Tomography

ERCP: Endoscopic retrograde cholangiopancreatography

EUS FNA: Endoscopic Ultrasound

FNA: Fine needle aspiration

FNA: Fine needle biopsy

HCC: Hepatocellular carcinoma

ROSE: Rapid on site evaluation

\section{REFERENCES}

1. Gerhards MF, Vos P, van Gulik TM, Rauws EA, Bosma A, Gouma DJ. Incidence of benign lesions in patients resected for suspicious hilar obstruction. Br J Surg. 2001;88:48-51.

2. Batra Y, Pal S, Dutta U et al. Gallbladder cancer in India: a dismal picture. J GastroenterolHepatol 2005; 20:309-14.

3. Wakai T, Shirai Y, Sakata J et al. Clinicopathological features of benign biliary strictures masquerading as biliary malignancy. Am Surg. 2012; 78:1388-91.

4. Corvera CU, Blumgart LH, Darvishian F et al. Clinical and pathologic features of proximal biliary strictures masquerading as hilar cholangiocarcinoma. J Am Coll Surg. 2005;201:862-9.

5. Howell DA, Beveridge RP, Bosco J, Jones M. Endoscopic needle aspiration biopsy at ERCP in the diagnosis of biliary strictures. GastrointestEndosc 1992; 38: 531-5.

6. Jailwala J, Fogel EL, Sherman S et al. Triple tissue sampling at ERCP in malignant biliary obstruction. GastrointestEndosc. 2000;51:383-90.

7. Ponchon T, Gagnon P, Berger Fet al. Value of endobiliary brush cytology and biopsies for the diagnosis of malignant bile duct stenosis: results of a prospective study. GastrointestEndosc. 1995;42:56572.

8. Fritscher-Ravens A, Broering DC, Sriram PVet al. EUS-guided fine-needle aspiration cytodiagnosis of hilar cholangiocarcinoma: a case series. GastrointestEndosc. 2000;52:534-40.

9. Fritscher-Ravens A, Broering DC, Knoefel WT et al. EUS-guided fine-needle aspiration of suspected hilar cholangiocarcinoma in potentially operable patients 
Singla V, et al, Tissue acquisition for diagnosis of proximal biliary lesions using endoscopic ultrasound-guided

with negative brush cytology. Am J Gastroenterol. 2004;99:45-51.

10. DeWitt J, Misra VL, Leblanc JK, McHenry L, Sherman S. EUS-guided FNA of proximal biliary strictures after negative ERCP brush cytology results. GastrointestEndosc. 2006;64:325-33.

11. Eloubeidi MA, Chen VK, Jhala NC et al. Endoscopic ultrasound-guided fine-needle aspiration biopsy of suspected cholangiocarcinoma. Clin Gastroenterol Hepatol. 2004;2:209-13.

12. Rösch T, Hofrichter K, Frimberger Eet al. ERCP or EUS for tissue diagnosis of biliary strictures? A prospective comparative study. GastrointestEndosc. 2004;60:390-6.

13. Singla V, Agarwal R, Anikhindi SA et al. Role of EUSFNA for gallbladder mass lesions with biliary obstruction: a large single-center experience. Endosc Int Open. 2019;7(11):E1403-E1409.

14. Téllez-Ávila FI, Bernal-Méndez AR, GuerreroVázquez CG, Martínez-Lozano JA, Ramírez-Luna MÁ. Diagnostic yield of EUS-guided tissue acquisition as a first-line approach in patients with suspected hilar cholangiocarcinoma. Am J Gastroenterol. 2014;109:1294-6.

15. Weilert F, Bhat YM, Binmoeller KF et al. EUS-FNA is superior to ERCP-based tissue sampling in suspected malignant biliary obstruction: results of a prospective, single-blind, comparative study. GastrointestEndosc. 2014;80:97-104.

16. Mohamadnejad M, DeWitt JM, Sherman Set al. Role of EUS for preoperative evaluation of cholangiocarcinoma: a large single-center experience. GastrointestEndosc. 2011;73:71-8.

17. Nayar MK, Manas DM, Wadehra V, Oppong KE. Role of EUS/EUS-guided FNA in the management of proximal biliary strictures. Hepatogastroenterology. 2011;58:1862-5

18. Clayton RA, Clarke DL, Currie EJ, Madhavan KK, Parks RW, Garden OJ. Incidence of benign pathology in patients undergoing hepatic resection for suspected malignancy. Surgeon. 2003;1:32-8.

19. Wetter LA, Ring EJ, Pellegrini CA, Way LW. Differential diagnosis of sclerosing cholangio carcinomas of the common hepatic duct (Klatskin tumors). Am J Surg 1991;161:57 62.

20. Sadeghi A, Mohamad nejad $M$, Islami $F$ et al Diagnostic yield of EUS-guided FNA for malignant biliary stricture: a systematic review and metaanalysis. Gastrointest Endosc. 2016;83:290-8.

21. Athanassiadou P and Grapsa D. Value of endoscopic retrograde cholangiopancreatography guided brushings in preoperative assessment of pancreaticobiliary strictures. Acta Cytologica 2011;52:24-34

22. Glasbrenner B, Ardan M, Boeck W, Preclik G, Möller P, Adler G. Prospective evaluation of brush cytology of biliary strictures during endoscopic retrograde cholangio pancreatography. Endoscopy. 1999;31:7127.

23. Pugliese V, Conio M, Nicolò G, Saccomanno S, Gatteschi B. Endoscopic retrograde forceps biopsy and brush cytology of biliary strictures: a prospective study. GastrointestEndosc. 1995;42:520-6.

24. Schoefl R, Haefner M, Wrba Fet alForceps biopsy and brush cytology during endoscopic retrograde cholangio pancreatography for the diagnosis of biliary stenoses. Scand J Gastroenterol. 1997;32:363-8.

25. Burnett AS, Calvert TJ, and Chokshi RJ. Sensitivity of endoscopic retrograde cholangio pancreatography standard cytology: a review of the literature. J Surg Res 2013;184:30411.

26. Lee YN, Moon JH, Choi HJ et al. Tissue acquisition for diagnosis of biliary strictures using peroralcholangioscopy or endoscopic ultrasoundguided fine-needle aspiration. Endoscopy. 2019;51:50-59.

27. Sethi A, Chen YK, Austin GLet al. ERCP with cholangio pancreatoscopy may be associated with higher rates of complications than ERCP alone: a single-center experience. Gastrointest Endosc. 2011;73:251-6.

28. Heimbach JK, Gores GJ, Haddock MGet al. Predictors of disease recurrence following neoadjuvant chemoradiotherapy and liver transplantation for unresectable perihilar cholangiocarcinoma. Transplantation. 2006;82:1703-7. 
Singla V, et al, Tissue acquisition for diagnosis of proximal biliary lesions using endoscopic ultrasound-guided

29. Rea DJ, Heimbach JK, Rosen CBet al. Liver transplantation with neoadjuvant chemoradiation is more effective than resection for hilar cholangiocarcinoma. Ann Surg. 2005;242:451-8.

30. Heimbach JK, Sanchez W, Rosen CB, Gores GJ. Trans-peritoneal fine needle aspiration biopsy of hilar cholangiocarcinoma is associated with disease disemination. HPB 2011; 13:356 360 .
31. Gleeson FC, Rajan E, Levy MJet al. EUS-guided FNA of regional lymph nodes in patients with unresectable hilar cholangiocarcinoma. GastrointestEndosc. 2008;67:438-43. 